\title{
The role of breeding in sports performance and health with special emphasis on lameness prevention
}

\author{
A. Barneveld \\ Department of General and Large Animal Surgery, Faculty of Veterinary Medicine, Utrecht, The Netherlands
}

\begin{abstract}
Summary
The selection system of the Royal Warmblood Studbook of the Netherlands (KWPN) is reviewed with the objective of evaluating the role of breeding in equine health and performance. The pillars of this breeding system involve evaluation of conformation and movements, constitution and health prerequisites, character, abilities and willingness in training, and evaluation of offspring. The system is adjusted according to the results of research projects which include a radiologic progeny study, a kinematic analysis of subjective jury scoring and the accuracy of predicting future movements by judging a foal's gait.
\end{abstract}

Keywords: $\quad$ warmblood horses, breeding, selection, conformation, performance

\begin{abstract}
Die Bedeutung der Zucht für Leistungsfähigkeit und Gesundheit mit besonderer Betonung der Prävention von Lahmheiten
Es wird eine Übersicht über das Selektionssystem des Königlich Niederländischen Warmblutstutbuches (KWPN) gegeben, mit schwerpunktmäßiger Untersuchung der Bedeutung der Zucht für die Gesundheit und das Leistungsvermögen der Pferde. Dieses Zuchtsystem beruht auf den folgenden Grundsätzen: Beurteilung von Exterieur und Bewegungen, Konstitution und gesundheitliche Voraussetzungen, Charakter, Fähigkeiten und Willigkeit im Training, sowie Beurteilung der Nachkommen. Das System wird an die Resultate von Forschungsprojekten angepaßt, darunter eine radiologische Nachkommenuntersuchung, eine kinematische Analyse in Beziehung zum subjektiven Urteil einer Jury und eine Studie, in der die Vorhersage späterer Bewegungen anhand der Beurteilung der Gänge im Fohlenalter überprüft wird.
\end{abstract}

Schlüsselwörter: Warmblutpferde, Zucht, Selektion, Exterieur, Leistungsfähigkeit

\section{Introduction}

All over the world the goal of horse breeding is to enhance the performance of the progeny in racing, sport or pleasure riding. In many countries breeding is strictly regulated, often with well-defined breeding aims. In other countries there are no rules at all. In the Netherlands, the role of the government has always been limited and now is virtually non-existant. The Netherlands does not have a national stud and the government does not interfere with breeding affairs. The different horse- and pony-studbooks are free to settle their own rules for breeding. Until recently the only regulation was the Horse Act of 1939 that prohibited the service of stallions not registered in any of the studbooks. With the unification of Europe, however, this Act has been cancelled.

In the Netherlands, the most important horse breed is the Dutch Warmblood. The Royal Warmblood Studbook of the Netherlands (KWPN) recognises three categories of horses: riding horses (85\%), driving horses, and "basic" horses. The latter group is the smallest and consists of the genuine farm horses that were the foundation for both other groups. The KWPN registers about 11,000 foals from riding horses every year, and 1,000 foals from driving and basic horses combined. The present paper will focus on Dutch Warmblood breeding, and in particular on the category of riding horses.

Dutch Warmblood horse breeding is only partly in the hands of professionals. All stallions are privately owned, mostly by people who have made breeding their profession. The majority of mares, however, are in the possession of people who breed horses for pleasure. The average number of mares per breeder is two. At present, the KWPN has more than 26,000 members.

Many Dutch Warmblood sport horses perform in the international limelight and the achievements of these dressage, jumping and driving horses have given Dutch Warmblood horses an excellent reputation. The breeding of KWPN horses has been based on two basic conditions: the expertise, feeling, understanding and involvement of the individual breeder and the development and implementation of a breeding and selection programme that is followed by the members in spite of the often far-reaching consequences for the individual horse owner. The selection system of the KWPN is one of the strictest in the world: of the more than 5,500 colts born every year no more than about fifteen pass the selection system for breeding stallions (sires). Such a far-reaching breeding programme needs thorough verification and various aspects of the programme have been evaluated scientifically over the last fifteen years. For thirty years veterinary examinations have formed an important part of the KWPN selection system. The importance of good health is beyond all doubt. These days, most sport horses end their career prematurely due to health problems, and statistics from equine insurance companies show that chronic lamenesses are the main reason for culling sport horses. This emphasises the fact that a healthy constitution is the first prerequisite for a long and prosperous career as a sport horse. 
The aim of the present paper is to discuss the role of breeding in relation to performance and health by reviewing the selection system of the Royal Warmblood Studbook of the Netherlands. The KWPN has a clear breeding aim and the philosophy that a strict selection on the basis of physical and physiological characteristics is inevitable. Conformation and movements, constitution and health prerequisites, character, abilities and willingness in training, and evaluation of offspring are the pillars of this breeding system. In the statutes of the KWPN it has been laid down that they intend to support their approach to breeding with scientific data. In the field of health, three studies have been conducted recently: a radiological progeny study to evaluate the effectiveness of the radiological screening programme for the breeding stallions, a kinematic study to compare subjective jury scoring of the trot with kinematic analysis scores, and another kinematic study to evaluate the accuracy with which gait and performance as an adult horse could be predicted by judging a foal's gait.

\section{Breeding aim and heritability}

The aim of the KWPN is to breed a performance horse with a healthy constitution, functional conformation, correct movements, and an appealing appearance (KWPN 1995).

Breeding involves thinking in terms of generations and small modifications in the appearance and/or performance of horses will take decades to be established due to the long generation interval. Breeding has various aspects but it mainly means selection. Selection is necessary to preserve the qualities required for a performance horse while abandoning any characteristics that might interfere with optimal performance. Both sire and dam influence their offspring, but in terms of numbers the influence of the sire on the population is much greater. A very fertile mare may deliver 15-20 foals, while a stallion can easily produce 1000 or more offspring. Consequently, selection is more effective on the male side and therefore should be more rigorous with respect to the sires.

Many traits and diseases have a significant heritability, which measures the degree to which inheritance plays a role in the trait or in the disease. The heritability gives an indication whether it is useful to select for a certain trait or disease or not. If the heritability is less than 0.15 , selection will hardly have any effect, some effect may be expected between 0.15 and 0.25 , and above 0.25 considerable progress can be made.

\section{Conformation and movements}

Within the KWPN, conformation (exterior) and movements (locomotion) have always played an important role in the selection of horses.

Only approved stallions are allowed to service mares, and any stallion that enters the annual stallion examination is evaluated on the basis of five criteria: exterior (conformation), movements, total pedigree, significance of sire and dam's pedigree, and sports value of the total pedigree. The KWPN is trying to express conformation objectively using a conformation index based on linear scoring (discussed later), and to express sport value objectively using a sport index.

Mares are not excluded from breeding, but there is a self regulating mechanism. Annual 'Studbook inspections' have the objective to determine whether a mare qualifies for registration in the Studbook. When unacceptable faults are found in conformation and/or movements, the mare will not qualify for registration in the Studbook. Although this does not formally exclude a mare from bree- ding, that is what actually happens. Mares that have qualified as three-year-olds for Studbook registration may be awarded premiums. There are six kinds of premiums. The 'star premium' (='ster') is given to mares that have a high standard of conformation and movement. A 'selection premium' (='keur') is awarded to mares that have a 'star premium', have done a performance test, and have produced and shown acceptable offspring. The 'elite premium (='elite') is given to mares with a 'selection premium' that have passed the same radiologic examination as the approved stallions. The 'sport premium' (='sport') is given to a mare, registrated in the Studbook, that performs at a certain (high) level in dressage, jumping, eventing, or driving. The 'preferential premium' (='preferent') is given if a mare has delivered at least three offspring that have been awarded 'star premiums' or comparable results in other studbooks. The 'performance premium' (='prestatie') is given to mares that have produced at least three offspring showing good sport results at a certain (high) level. The later two premiums can be awarded posthumously.

\section{Constitution and health prerequisites}

The useful life (durability) of a sport horse depends on a number of factors: genetic traits concerning health and soundness, and the way it was reared, fed, trained and used. The quality of the locomotor system is one of the main factors affecting durability. Navicular disease, sesamoidosis, arthrosis of the fetlock joint, bone spavin and osteochondrosis are the most common causes of chronic lamenesses.

For several decades, Dutch Warmblood stallions admitted for breeding purposes have been required to pass veterinary examinations and these have become more strict in due course. Since the beginning of the eighties, there have been extensive clinical, radiological, laryngoscopic (particularly for hemiplegia) examinations and basic requirements for sperm quality. Radiographs of the navicular bones (lateromedial and upright pedal dorsopalmar views), sesamoid bones and fetlock joints (dorsomedial-palmarolateral and dorsolateral-palmaromedial oblique views) are taken from both forelimbs. In the hind limbs the tarsal joint (lateromedial, dorsoplantar, and dorsolateral-plantaromedial oblique views), and stifle joint (lateromedial view) are radiographed. The results of the radiological examination are classified from 0 up to and including 4. In this scale 0 means perfect or almost perfect with a very small risk of developing lameness, while 4 means bad or very bad with a very high lameness risk. Class 4 makes a stallion unacceptable for breeding. If the radiographs of tarsal or stifle joints show osteochondrotic lesions the stallion is also excluded from breeding.

For the mares there is a voluntary project to evaluate the radiographic quality of their limbs similar to the procedure in stallions. The results of radiographic examination of the stallions approved for breeding are published. This allows the breeder to select an optimal partner, especially if the radiological features of the mare, are known.

\section{Character, abilities and willingness in training}

Apart from conformation, movements and health, great importance should be attached to the horse's character, including traits such as attitude to work, abilities, maximum usability and willingness to give that last little bit when asked for it.

Since 1966, all three-year old stallions that have been selected as potential sires at the central stallion show have been obliged to 
take part in the Central Performance Test. During 70 days training at a central location their achievements are regularly assessed and tested by a training committee and riders who have international experience in jumping or dressage. As these stallions are tested in a similar environment by a small group of riders, genetic differences can be distinguished more clearly. The genetic relationship (heritability) between the performance tests of stallions and the sport results of their offspring is high: Huizinga et al. (1991) estimated the heritability for gaits and riding ability to be 0.64 , for cross country to be 0.41 and for jumping to be 0.31 . They also found that the estimated genetic correlation between the show jumping scores of breeding stallions at the Central Performance Test and jumping in competition from their offspring is 0.84 , for dressage this relation is 0.83 .

Stallions of 7 years and older whose records in sport or breeding are considered "satisfactory" by the board of directors are also required to take part in the testing for a period of 21 to 50 days.

For decades there has been a simple one-day performance test for mares, geldings and not-approved stallions (IBOP-test). As the Central Performance Test for stallions proved to have great prognostic value, recently central training and testing facilities have been organised for qualifying mares on the basis of the same principles as applied to the stallions. These Mare Performance Tests take five weeks during which mares are trained and objectively evaluated by a group of experienced trainers and riders.

\section{Evaluation of offspring}

To evaluate the offspring of a sire, the KWPN uses two indexes: the sport index and the conformation index.

The sport index was introduced in 1987 and is not unique. The KWPN uses it for orientation of the breeders. The sport index is based on the best sport results, either in jumping or in dressage, that have ever been realised by a sire's offspring. Collection of these data has been made possible by computerisation and the willingness of sport-organisations to use the lifenumbers of horses allocated by the studbook organisations. All these data result in a figure that indicates in which aspect a sire's hereditary capacities are strongest and to what degree. The higher the index figure, the greater the sire's significance as a progenitor of sport horses. At a dressage or jumping index figure of 100 his influence is nil, below 100 it is negative and above 100 it is positive. A sire's influence becomes really significant when the sport-index figure is above 120.

The sport results of all descendants of a stallion can be evaluated each year and at any stage the Studbook can withdraw a stallion that is no longer able to contribute to the improvement of the breed in general.

The conformation index was introduced in 1990 and is only used by the KWPN. It indicates how a sire passes on certain conformation components (e.g. a long or a short shoulder length or a steep or a straight croup angle). The conformation index of a sire is based on the linear scoring of his offspring. Linear scoring is done by area inspectors at selection days for each three-year old horse (mare, stallion or gelding) presented for registration. On a special linear scoring form 26 qualities are scored from 0 up to and including 40, 20 being the population average and 0 and 40 the biological extremes (Koenen et al. 1995). Twenty conformation traits considering front, body and rear, and legs are evaluated as the horse stands still in front of the jury, the other six, which evaluate movement components (length of stride, suppleness and correctness of the walk and length of stride, suppleness and impulse of the trot) are rated while the horse is walked and trotted at hand. The results are entered in a computer and corrected for date and location of selection, inspector, gender, age and percentage of thoroughbred blood, as these factors have no hereditary relevance. The degree of heredity of the 26 characteristics varies from 0.11 up to and including 0.26 . One of the lowest heredity degrees is stride length (roominess) of the walk (0.11), while neck length has one of the highest $(0.26)$.

At least half of the 26 characteristics, are related to the health of the horse, e.g. height at withers, conformation of back and loins, correctness of fore and hind limbs and quality of the bones.

The linear scoring and the computer evaluation of conformation breeding values have been determined since 1990. If a breeder knows the shortcomings and the better features of his broodmare, the conformation index can help him to choose a suitable stallion. In the past, after a stallion had performed his first year of service, the owner was obliged to show a minimum of 16 foals, half of which was picked at random by the Studbook, the other half was chosen by the owner. If this inspection was satisfactory, these foals would be evaluated as three-year-olds on the basis of the linear scoring system. This has been abandoned recently as it was possible for owners to influence the results of these foal inspections by preparing the foals. Now, the contribution of a stallion's progeny to the population is evaluated at three moments:

* when the oldest progeny are three-year olds, they are evaluated for conformation on 'Studbook inspections'. This provides the first figure for the conformation index of the stallion

* when the oldest progeny are seven-year olds, both the sport index and conformation index of the stallion are evaluated

* this is repeated when the oldest offspring are eleven-year olds

\section{Radiographic progeny study}

The aim of the progeny study was to assess the frequency of podotrochleosis, sesamoidosis, fetlock arthrosis, spavin and osteochondrosis in the tarsal and stifle joints in order to estimate the heritability of these diseases.

The horses selected for the project were 30 stallions born in 1982 , 1983 , or 1984 that had at least 30 registered 3-year old daughters. A total of 590 female offspring came to the Faculty in Utrecht for radiographic examination. The mares were radiographically evaluated as described above. For each mare the highest (worst) score for each subject was taken as being representative, since a horse is a good as its worst limb. Three of these diseases (navicular disease, spavin and osteochondrosis) have been shown to have a high heritability (table 1), while the other two conditions seem less heritable (van der Meij et al. 1994).

Tab. 1: Heritability of radiological scoring of different bones in the equine limb (van der Meij et al. 1994).

\begin{tabular}{|l|l|}
\hline bone & heritability \\
\hline navicular bone & $0.26-0.34$ \\
\hline sesamoid bone & $0.11-0.17$ \\
\hline fetlock arthrosis & $0.13-0.26$ \\
\hline spavin & $0.20-0.35$ \\
\hline osteochondrosis & $\pm 0.25^{*}$ \\
\hline
\end{tabular}

*the heritability of osteochondrosis was estimated from the results of the study supplemented with data from the literature 
The conclusions of the project are that stallions with grades 3 and 4 navicular bones, grade 4 fetlock arthrosis, grades 3 or 4 spavin, or osteochondrosis in the tarsal or stifle joints are refused, while stallions with grade 4 sesamoid bones are now accepted.

\section{Objective evaluation of a horse's trot}

It has been shown that it is possible to evaluate the trot objectively by means of a computerised gait analysis system (Back et al. 1994a). The trot of 24 26-month-old Dutch Warmbloods, led on a loose shank, was subjectively scored by an experienced judge and objectively assessed on a treadmill using kinematic analysis equipment. For the latter, special markers glued to the skin overlying palpable skeletal landmarks were used to detect three light beams emitted by a scanner. From the data the computer calculates the kinematics of gait. A judge, using the linear scoring system, evaluates three qualities of the trot: roominess (length), suppleness and impulse (strength). Comparing the judge's score with the kinematic variables, it was found that horses considered "better movers" by the judge, had a greater fetlock extension in the forelimb, an increased scapular rotation and more flexion in the stifle and tarsal joints. The larger fetlock extension might be explained by the fact that the spring-like action of the forelimb fetlock joint reduces the shock of limb-ground contact and smoothness of gait, which may be interpreted by the judge as suppleness. A large range of motion in the scapula is essential to increase the stride length, seen by the judge as roominess. More flexion in the stifle and tarsal joints possibly adds to the impulse. In the same study the ranking of the individual horses on the basis of gait quality according to their objectively measured kinematic variables was similar to the subjective ranking given by the judge.

\section{Predictive value of a foal's gait}

Another study investigated the development of gait from foal age to adulthood. The forelimb kinematics of 24 Dutch Warmbloods were recorded at trot on a treadmill $(4 \mathrm{~m} / \mathrm{s})$ at the age of $4,10,18$ and 26 months using the same kinematic analysis system as described above. Stride and stance duration increased with age, but swing duration and pro- and retraction angles were consistent. The timing of maximal fetlock extension during the stance phase and carpal flexion during the swing phase did not significantly change as the horses grew older. It was concluded that horses have an inherited intralimb coordination pattern, visible in the kinematic data as a "fingerprint", that does not change with age. This indicates that evaluation of a foal's locomotion might have good predictive value for the adult locomotor pattern. However, as mentioned above, foal inspections are not in the breeding programme as it proved possible for owners to influence the results in an unacceptable manner. If a method is found to decrease this influence, foal inspections might again be introduced in the breeding programme.

\section{Discussion and conclusions}

It is clear that health plays a major role in the KWPN breeding programme. All of the important criteria in the breeding programme have a health component. At least half of the characteristics that are scored in the conformation evaluation are related to health. Correct movements, a prerequisite for long lasting future athletic ability, are important in the breeding philosophy. In the sport index, performance at a high level is particularly influential in determining the score. Since this type of performance requires a long and strenuous period of training, this also proves a healthy constitution. The premiums obtained in the pedigree also demonstrate the healthy constitution of the dams.

The breeding programme is continuously modified as the results of scientific research become available. For example, the radiographic progeny study has resulted in the acceptance of grade- 4 sesamoid bones for a breeding stallion as the heritability proved to be low. In future the predictive value of a foal's trot will facilitate evaluation of horses at a younger age.

In conclusion: health and performance are inextricable bound together. By selecting horses with a healthy constitution, functional conformation and correct movements, the KWPN will maximise the chances of producing horses than can perform at the highest levels of competition.

\section{References and further reading}

Anonymus (1994): De regels van het stamboekwezen 1994. KWPN, Zeist, the Netherlands, $67 \mathrm{pp}$.

Anonymus (1995): Notitie fokbeleid rijpaarden. Fokkerijraad October 23, 1995, $8 \mathrm{pp}$.

Anonymus (1995): General rules of the KWPN. In: Programme of the KWPN stallions show 1995, 's Hertogenbosch, 260 pp.

Back, W., van den Bogert, A. J., van Weeren, P. R., Bruin, G. and Barneveld, A. (1993): Quantification of the locomotion of Dutch Warmblood foals. Acta Anat. 146, 141-147.

Back, W., Barneveld, A., Schamhardt, H. C., Bruin, G. and Hartman, W. (1994a): Longitudinal development of the kinematics of 4-, 10-, 18- and 26-month-old Dutch Warmblood horses. Equine Vet. J., suppl. 17, 3-6.

Back, W., Barneveld, A., Bruin, G., Schamhardt, H. C. and Hartman, W. (1994b) Kinematic detection of superior gait quality in young trotting warmbloods. Vet. Quart., 16, S91-96.

Huizinga, H. A., Werf, J. H. J. van der, Korver, S. and Meij, G. J. W. van der (1991) Stationary performance testing of stallions from the Dutch Warmblood riding horse population. 1. Estimated genetic parameters of scored traits and the genetic relation with dressage and jumping competition from offspring of breeding stallions. Livestock Production Science, 27, 231-244.

Koenen, E. P. C., Veldhuizen, A. E. van and Brascamp, E. W. (1995) Genetic parameters of linear scored conformation traits and their relation to dressage and show-jumping performance in the Dutch warmblood riding horse population. Livestock Production Science, 43, 85-94.

Meij, G. J. W. van der, Dik, K. J. and Barneveld, A. (1994): The frequency and heredity of navicular disease, sesamoidosis, fetlock joint arthrosis, bone spavin, osteochondrosis of the hock: a radiographic progeny study. KWPN, Zeist, the Netherlands, $47 \mathrm{pp}$.

Melissen, J. (1992): The leading stallions of the Netherlands. $1^{\text {st }}$ ed. Jacob Melissen BV, Pesse, the Netherlands, pp 227.

Melissen, J. (1994): The leading stallions of the Netherlands. $2^{\text {nd }}$ ed. Jacob Melissen BV, Pesse, the Netherlands, pp 365.

\section{Prof. Ab Barneveld, DVM, PhD}

Department of General and Large Animal Surgery

Faculty of Veterinary Medicine

Yalelaan 12

3584 CM Utrecht

The Netherlands

phone 31302531350 fax 31302537970 